\title{
A Human Periodontal Ligament Fibroblast Cell Line as a New Model to Study Periodontal Stress
}

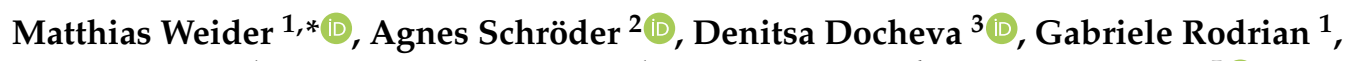 \\ Isabel Enderle ${ }^{1}$, Corinna Lesley Seidel ${ }^{1}$, Darja Andreev ${ }^{4}$, Michael Wegner ${ }^{5}{ }^{\circ}$, Aline Bozec ${ }^{4}$, \\ James Deschner ${ }^{6}$, Christian Kirschneck ${ }^{2}{ }^{\oplus}$, Peter Proff ${ }^{2}$ and Lina Gölz ${ }^{1}$ \\ 1 Department of Orthodontics and Orofacial Orthopedics, University Hospital of Erlangen, \\ Friedrich-Alexander University Erlangen-Nuernberg, Glueckstr. 11, 91054 Erlangen, Germany; \\ gabriele.rodrian@uk-erlangen.de (G.R.); isabel.enderle@uk-erlangen.de (I.E.); \\ corinna.boeck@uk-erlangen.de (C.L.S.); lina.goelz@uk-erlangen.de (L.G.) \\ 2 Department of Orthodontics, University Hospital Regensburg, Franz Josef Strauss Allee 11, \\ 93053 Regensburg, Germany; agnes.schroeder@ukr.de (A.S.); christian.kirschneck@ukr.de (C.K.); \\ peter.proff@ukr.de (P.P.) \\ 3 Experimental Trauma Surgery, Department of Trauma Surgery, University Hospital Regensburg, \\ Franz Josef Strauss Allee 11, 93053 Regensburg, Germany; denitsa.docheva@ukr.de \\ 4 Department of Medicine 3, Rheumatology and Immunology, University of Erlangen-Nuremberg, \\ Glueckstr. 6, 91054 Erlangen, Germany; darja.andreev@uk-erlangen.de (D.A.); \\ aline.bozec@uk-erlangen.de (A.B.) \\ 5 Institut für Biochemie, Emil-Fischer-Zentrum, Friedrich-Alexander-Universität Erlangen-Nürnberg, \\ Fahrstr. 17, 91054 Erlangen, Germany; michael.wegner@fau.de \\ 6 Department of Periodontology and Operative Dentistry, \\ University Medical Center of the Johannes Gutenberg University, 55131 Mainz, Germany; \\ james.deschner@uni-mainz.de \\ * Correspondence: matthias.weider@uk-erlangen.de; Tel.: + 49-9131-85-45653
}

Received: 29 September 2020; Accepted: 23 October 2020; Published: 27 October 2020

\begin{abstract}
The periodontal ligament (PDL) is exposed to different kinds of mechanical stresses such as bite force or orthodontic tooth movement. A simple and efficient model to study molecular responses to mechanical stress is the application of compressive force onto primary human periodontal ligament fibroblasts via glass disks. Yet, this model suffers from the need for primary cells from human donors which have a limited proliferative capacity. Here we show that an immortalized cell line, PDL-hTERT, derived from primary human periodontal ligament fibroblasts exhibits characteristic responses to glass disk-mediated compressive force resembling those of primary cells. These responses include induction and secretion of pro-inflammatory markers, changes in expression of extracellular matrix-reorganizing genes and induction of genes related to angiogenesis, osteoblastogenesis and osteoclastogenesis. The fact that PDL-hTERT cells can easily be transfected broadens their usefulness, as molecular gain- and loss-of-function studies become feasible.
\end{abstract}

Keywords: mechanical loading; orthodontic tooth movement; bone remodeling; cell culture techniques

\section{Introduction}

The periodontal ligament (PDL) is a thin sheet-like structure surrounding teeth, serving to anchor teeth in alveolar bones. It consists of different kinds of connective tissue fibers. This tissue has a high capacity of proliferation and of remodeling, enabling a constant width, despite different kinds of mechanical stress such as occlusal pressure and orthodontic force [1,2]. PDL fibroblasts are the main cells surrounding teeth, besides osteoblastic lineages constituting the bones. These fibroblasts fulfill a rich 
repertoire of functions such as tissue homeostasis and the establishment of a collagenous extracellular matrix (ECM) by secreting structural proteins, but also regulatory functions in defense reactions of the innate immune system [1,2]. PDL fibroblasts also play a major role in sensing and mediating mechanical load during occlusion of teeth in development and during orthodontic tooth movement (OTM) $[3,4]$. They sense compressive or tensile forces and trigger pro-inflammatory responses. One of the first steps within this process of mechanotransduction is the induction of prostaglandin-endoperoxide synthase 2 (PTGS2, also called cyclooxygenase 2), which catalyzes the synthesis of the eicosanoid prostaglandin $\mathrm{H} 2$ from arachidonic acid [5,6]. Prostaglandin $\mathrm{H} 2$ is then converted to different eicosanoids such as prostaglandin E2 (PGE2) by other enzymes. These eicosanoids fulfill functions in diverse physiological reactions such as inflammation and other immune responses, regulation of cell growth and of blood pressure [5,6].

To enable OTM, alveolar bone has to be resorbed by osteoclasts. Cytokines controlling the proliferation and differentiation of osteoclast precursors are macrophage colony stimulatory factor (M-CSF) and receptor activator of nuclear factor kappa-B ligand (RANK-L), both of which are induced during OTM [7-11]. Thus, OTM is enabled by a pseudo-inflammatory reaction with bone resorption as the rate-limiting step [12]. Besides bone resorption, an extensive re-organization of the ECM also takes place during OTM [13,14]. This includes degradation of old ECM by matrix metalloproteases [15] as well as deposition of new collagen fibrils [14]. Other factors induced during OTM include vascular endothelial growth factor A (VEGF-A), a mitogen promoting angiogenesis and vasculogenesis [7] and alkaline phosphatase (ALPL), which plays a role in bone mineralization [16].

A well-established model to study mechanical stress on PDL (as it happens in the early phases of OTM) under in vitro conditions is the application of compressive force onto human periodontal ligament fibroblasts (hPDLF) [16-22]. This relies on the availability of primary hPDLF, demanding a constant supply with fresh cells from human donors. To facilitate research on OTM or mechanical stress on PDL fibroblasts in general, we set out to study the applicability of a cell line generated from hPDLF by lentiviral gene transfer of human telomerase reverse transcriptase (hTERT) resulting in stable transgene expression and cell immortalization [23]. We hypothesized that this cell line would respond to compressive force in a similar way as primary hPDLF and tested our hypothesis with established protocols.

\section{Results}

To investigate the response of the PDL-hTERT cell line to mechanical stress, we applied compressive force simulating early phases of orthodontic treatment in vitro according to well-established protocols $[3,16,19,24]$. Compressive force was applied with glass disks (Figure 1) for $6 \mathrm{~h}, 24 \mathrm{~h}, 48 \mathrm{~h}$ and $72 \mathrm{~h}$ referring to previous studies $[3,16,19,25]$.

compressive force

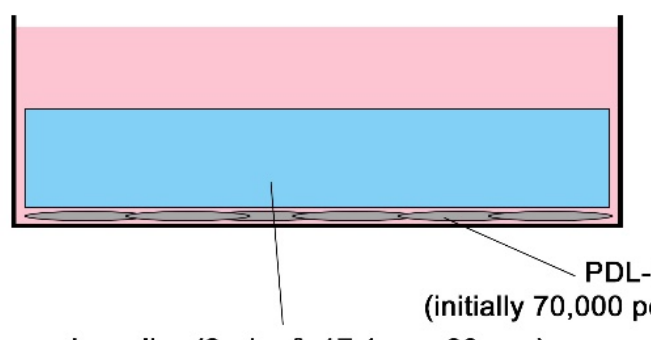

glass disc $\left(2 \mathrm{~g} / \mathrm{cm}^{2}, 17.1 \mathrm{~g}, ø 33 \mathrm{~mm}\right)$ control

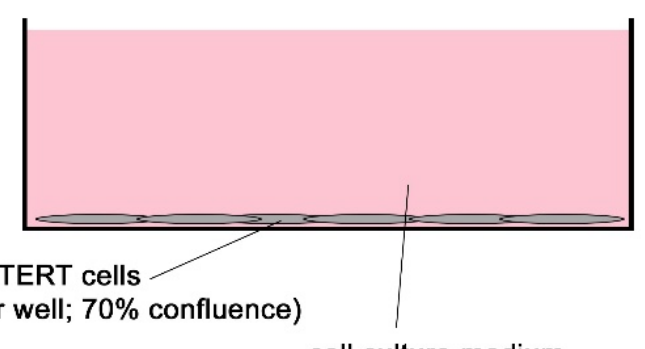

cell culture medium

Figure 1. In vitro model for compressive mechanical strain on PDL-hTERT cells. Compressive force is applied by sterile glass disks $\left(17.1 \mathrm{~g}, 2 \mathrm{~g} / \mathrm{cm}^{2}\right)$ onto PDL-hTERT cells growing adherently in 6 well cell culture plates under standard cell culture conditions in rich medium. Cells without glass disks serve as controls. Cells are incubated for different time spans and the amounts of analytes are referenced to the start of experiments $(T=0 \mathrm{~h})$ and to each respective control $(\mathrm{T}=6 \mathrm{~h}, 24 \mathrm{~h}, 48 \mathrm{~h}$ and $72 \mathrm{~h}$ ). 


\subsection{Kinetics of Pro-Inflammatory Markers in PDL-hTERT Cells}

Primary hPDLF respond to compressive force with an up-regulation of pro-inflammatory markers $[16,25]$. We therefore analyzed the expression of the pro-inflammatory genes interleukin-6 (IL-6) and prostaglandin-endoperoxide synthase 2 (PTGS2) in the PDL-hTERT cell line and the secretion of prostaglandin E-2 (PGE2) into cell culture medium upon exerting compressive force (Figure 2). As expected, we found a significant increase of these markers during the time course of our experiments. For $I L-6$, we already detected a statistically significant strong induction after $6 \mathrm{~h}$ of compressive load $(24.53 \pm 6.33$-fold over $\mathrm{T}=0 \mathrm{~h})$. The strongest induction was observed at $24 \mathrm{~h}$ (43.35 \pm 10.19$)$, followed closely by $48 \mathrm{~h}(39.84 \pm 17.94)$. At the last time point analyzed, expression of IL-6 had dropped to levels close to the start of the experiment (10.56 \pm 1.13$)$.
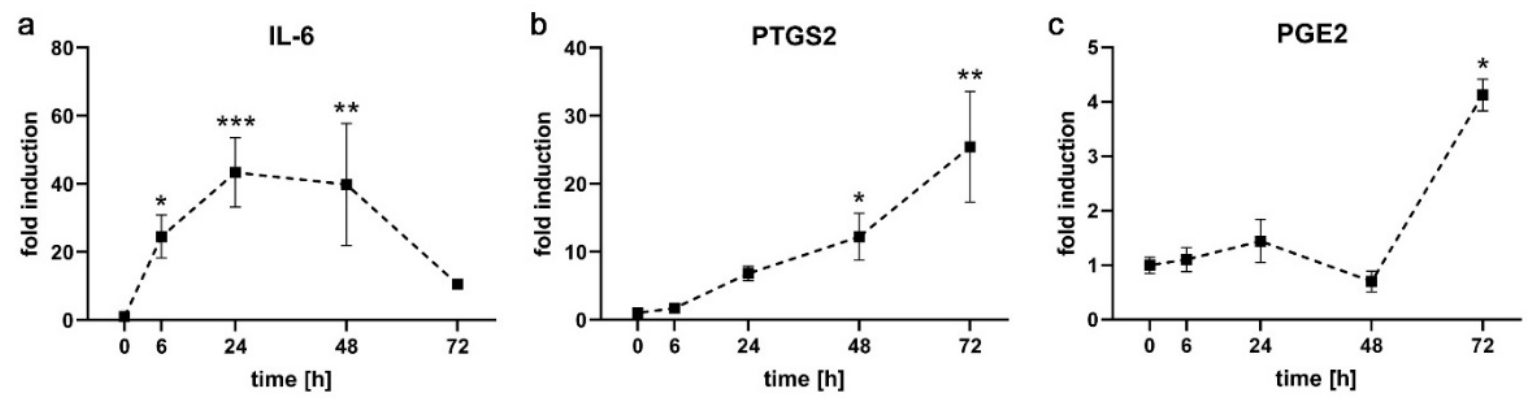

Figure 2. Kinetics of pro-inflammatory markers in PDL-hTERT cells under compressive load. Expression of pro-inflammatory genes $I L-6$ (a) and PTGS2 (b) at the specified time points was determined via qRT-PCR, amounts of PGE2 in cell culture medium were measured by ELISA (c). Values were referenced to arithmetic means at $\mathrm{T}=0 \mathrm{~h}$ and are shown as fold over non-treated controls at the respective time points \pm SEM. $n=2, n=6,{ }^{*} 0.01 \leq p<0.05,{ }^{* *} 0.001 \leq p<0.01,{ }^{* * *} 0.0001 \leq p<0.01$.

Expression of PTGS2 followed a slower time course. Induction was not seen until $24 \mathrm{~h}(6.82 \pm 1.06)$ and continuously rose $(12.23 \pm 3.45$ at $24 \mathrm{~h})$ until it reached its statistically significant maximum at $72 \mathrm{~h}$ (25.46 \pm 8.14$)$. Accordingly, levels of secreted PGE2 did not reach statistically significant induction until $72 \mathrm{~h}(1.11 \pm 0.23$ at $6 \mathrm{~h}, 1.45 \pm 0.40$ at $24 \mathrm{~h}, 0.70 \pm 0.19$ at $48 \mathrm{~h}$ and $4.13 \pm 0.30$ at $72 \mathrm{~h})$.

\subsection{Expression Kinetics of Genes Involved in Formation of Extracellular Matrix in PDL-hTERT Cells}

We then investigated the expression of genes involved in formation of extracellular matrix (ECM) because they are also known to be influenced in primary hPDLF by compressive force $[16,25]$. As representative genes, we chose Collagen alpha-2(I) chain (COL2A1), Prolyl 4-hydroxylase subunit alpha-1 (P4HA1) and Fibronectin (FN1) for analysis by qRT-PCR (Figure 3). All three genes showed a moderate induction during the time course of treatment, followed by decreases down to starting point levels (COL1A2: $1.26 \pm 0.09,1.41 \pm 0.22,1.14 \pm 0.22$ and $1.02 \pm 0.07$, P4HA1: $1.22 \pm 0.08,2.17 \pm 0.28$, $1.22 \pm 0.10$ and $1.61 \pm 0.22, F N 1: 1.29 \pm 0.17,1.49 \pm 0.23,1.32 \pm 0.16$ and $1.04 \pm 0.09$ at $6 \mathrm{~h}, 24 \mathrm{~h}, 48 \mathrm{~h}$ and $72 \mathrm{~h}$, respectively). Only the expression of $P 4 H A 1$ was significantly up-regulated after $24 \mathrm{~h}$.

\subsection{Expression Kinetics of Genes Involved in Angiogenesis, Osteoblastogenesis and Osteoclastogenesis}

Vascular endothelial growth factor A (VEGF-A) is a signaling molecule, which is essential for formation of blood vessels and is induced by compressive force in hPDLF [16,25]. Expression of $V E G F-A$ in PDL-hTERT cells started with a weak induction at $6 \mathrm{~h}(1.75 \pm 0.21)$, was robustly induced after $24 \mathrm{~h}(3.59 \pm 0.17)$ and dropped again to lower levels at later time points $(2.07 \pm 0.16$ at $48 \mathrm{~h}$ and $1.40 \pm 0.34$ at 72 h; Figure $4 a)$. 



Figure 3. Expression kinetics of genes involved in formation of extracellular matrix in PDL-hTERT cells under compressive load. Expression of COL1A2 (a), P4HA1 (b) and FN1 (c) at the specified time points was determined via qRT-PCR, values were referenced to arithmetic means at $\mathrm{T}=0 \mathrm{~h}$ and are shown as fold over non-treated controls at the respective time points \pm SEM. $n=2, n=6,{ }^{*} 0.01 \leq p<0.05$, *** $0.0001 \leq p<0.01$.
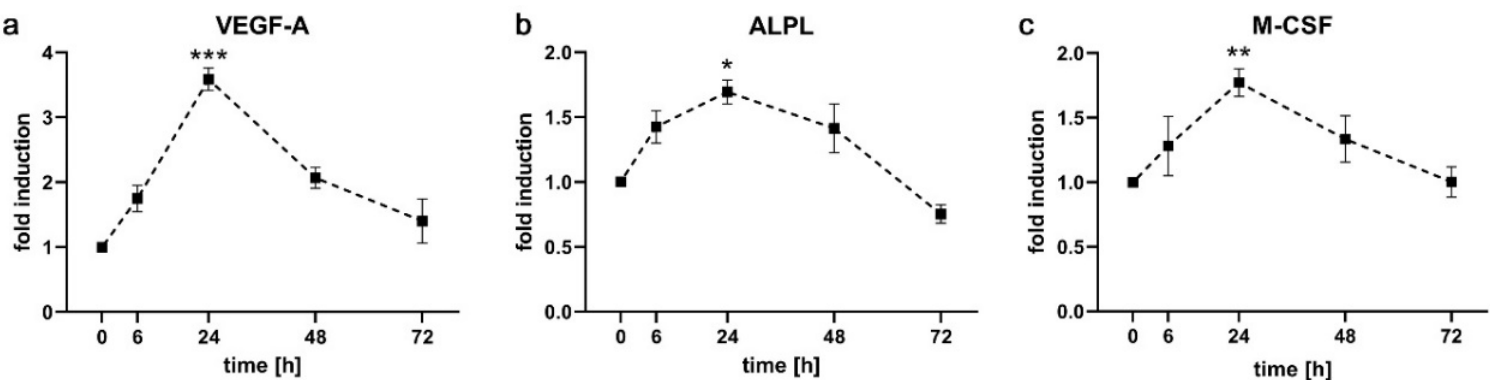

Figure 4. Expression kinetics of genes involved in angiogenesis, osteoblastogenesis and osteoclastogenesis in PDL-hTERT cells under compressive load. Expression of $V E G F-A$, involved in formation of blood vessels (a), ALPL, involved in formation of osteoblasts (b) and M-CSF, involved in differentiation of osteoclasts (c) at the specified time points was determined via qRT-PCR. Values were referenced to arithmetic means at $\mathrm{T}=0 \mathrm{~h}$ and are shown as fold over non-treated controls at the respective time points \pm SEM. $n=2, n=6,{ }^{*} 0.01 \leq p<0.05,{ }^{* *} 0.001 \leq p<0.01,{ }^{* * *} 0.0001 \leq p<0.01$.

Alkaline phosphatase (ALPL) plays a key role in skeletal mineralization and is also up-regulated during application of compressive force to hPDLF [16,25]. We could show a weak but statistically significant induction of ALPL in early phases of compressive force on PDL-hTERT cells $(1.43 \pm 0.12$ at $6 \mathrm{~h}, 1.69 \pm 0.09$ at $24 \mathrm{~h})$, which ceased again at later time points $(1.41 \pm 0.19$ at $48 \mathrm{~h}, 0.75 \pm 0.07$ at $72 \mathrm{~h}$; Figure $4 b)$.

M-CSF is one of the critical factors for activation of osteoclasts and its level in gingival crevicular fluid increases during OTM [7]. We could recapitulate this increase in our in vitro experiments, showing a weak induction at $6 \mathrm{~h}(1.28 \pm 0.23)$ that reached a statistically significant maximum at $24 \mathrm{~h}$ $(1.77 \pm 0.11)$ and decreased again to starting levels $(1.34 \pm 0.18$ at $48 \mathrm{~h}$ and $1.00 \pm 0.12$ at $72 \mathrm{~h}$; Figure $4 \mathrm{c})$.

\subsection{Transfection Efficiency of PDL-hTERT Cells}

A high transfection efficiency would allow a broad application of techniques for the PDL-hTERT cell line. We therefore tested transfection efficiency of PDL-hTERT cells with three different transfection reagents: Polyethylenimine (PEI), SuperFect and Lipofectamine 2000. Each reagent was used in two different concentrations. PEI and SuperFect yielded only minor transfection efficiencies $(1.20 \% \pm 0.25 \%$ and $1.10 \% \pm 0.20 \%$ with low and high amounts of PEI, and $1.20 \% \pm 0.26 \%$ and $1.17 \% \pm 0.23 \%$ with low and high amounts of SuperFect, respectively; Figure 5a,b). However, Lipofectamine 2000 in low amounts delivered reasonable transfection efficiency $(6.60 \% \pm 1.86 \%$; Figure $5 \mathrm{a}, \mathrm{b})$ with high cell viability $(76.5 \% \pm 21.06 \%$ of untransfected control cells; Figure $5 c)$. Increased amounts of Lipofectamine 2000 
yielded even higher transfection efficiencies $(9.77 \% \pm 2.04 \%)$ at the cost of cell viability $(39.60 \% \pm 19.57 \%$ of untransfected control cells; Figure 5a-c).
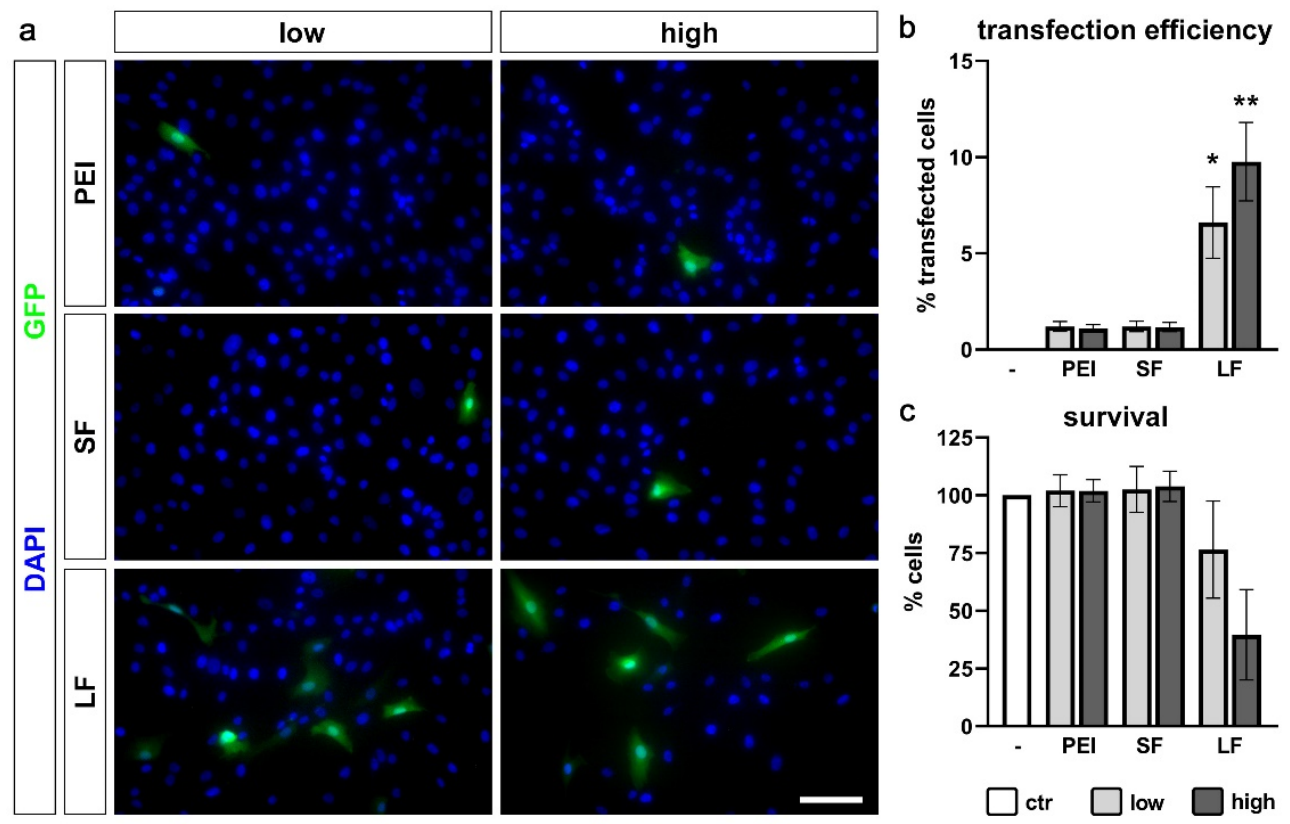

Figure 5. Transfection efficiency of PDL-hTERT cells. Cells were transfected with PEI, SuperFect (SF) and Lipofectamine 2000 (LF) in low and high amounts. (a) Representative images of GFP-positive transfected cells (green) and DAPI-stained nuclei of all cells (blue). Scale bar: $100 \mu \mathrm{m}$. (b) Quantification of transfection efficiency. GFP-positive transfected cells per field of view were set in relation to the number of DAPI-positive cell nuclei per field of view and are presented as $\% \pm$ SEM. Untransfected cells served as control (ctr). (c) Cell viability was calculated by counting DAPI-positive nuclei per field of view and set in relation to DAPI-positive nuclei per field of view of untransfected cells (ctr) and are presented as $\% \pm$ SEM. $n=3$ biological replicates performed as triplicates with three analyzed photographs per singlet. ${ }^{*} 0.01 \leq p<0.05,{ }^{* *} 0.001 \leq p<0.01$.

\section{Discussion}

In our in vitro study, we tested the potential of the immortalized human PDL-hTERT cell line to analyze effects of mechanical stress in the periodontium. Therefore, we followed well-established protocols of physiological compressive force of $2 \mathrm{~g} / \mathrm{cm}^{2}$ via glass disks that use primary hPDLF [16-21]. We expected similar responses of the PDL-hTERT cell line to compressive strain as of primary cells. When we investigated pro-inflammatory markers, we could see induction of the prostaglandin-endoperoxide synthase PTGS2 and increased secretion of the analyzed downstream product PGE2 into the medium. This is in line with previous in vitro findings using primary hPDLF $[3,16,26]$ and with the discovery of increased PGE2 levels in gingival crevicular fluid of human patients in early phases $(24 \mathrm{~h}$ and $48 \mathrm{~h}$ ) of OTM [27,28]. Moreover, we detected a strong, temporary induction of $I L-6$ gene expression that is also a characteristic response of primary hPDLF to mechanical load $[16,25,26,29]$.

Changes in the expression of ECM-related genes COL1A2, P4HA1 and FN1 were similar to the ones in primary hPDLF [16], with the exception that COL2A1 induction did not reach significance. This induction of ECM-reorganizing genes is also in accordance to animal models, where an increase in newly deposited collagen fibrils was seen after seven days of OTM [14].

We noticed an increased expression of angiogenesis-inducing VEGF- $A$, peaking at $24 \mathrm{~h}$ that resembled the situation in primary hPDLF [16]. Similarly, an increase in VEGF levels in gingival crevicular fluid of OTM patients was also detected after one day [7]. In contrast to in vitro models, levels of VEGF in patients remained high after seven days of treatment. The osteoblast marker ALPL showed 
a weaker induction than in primary hPDLF and the kinetics of its expression were faster. We also observed an induction of $M$-CSF, a cytokine controlling the differentiation of osteoclasts. This finding corresponds to reports demonstrating the induction of another osteoclastogenesis-inducing factor, $R A N K-L$, upon mechanical loading [16] and is in line with reports showing increased M-CSF levels within gingival crevicular fluid during OTM [7].

Summing up, the majority of markers we had chosen as examples responded in PDL-hTERT cells in a manner similar to primary hPDLF. As a note of caution, we would like to emphasize that we selected only a few central markers for processes such as inflammation, osteoblastogenesis or osteoclastogenesis. Therefore, it remains to be established if further markers share the same behavior. The time course of the response to compressive force by the PDL-hTERT cell line might be slightly different to primary hPDLF, as we detected some more rapid responses (for ALPL) but also some slower ones (for PTGS2) than in primary hPDLF [16]. We would like to point out that the majority of examined genes follow very similar kinetics as seen in primary hPDLF [16], which may indicate an identical behavior.

To enable molecular gain- and loss-of-function studies, we searched for an efficient transfection protocol for PDL-hTERT cells. Transfection of a homogeneous cell population might strongly improve genetic manipulations such as overexpression or knockdown of a specific gene of interest. Indeed, we found an efficient method using Lipofectamine 2000. As PDL-hTERT cells are relatively sensitive to this transfection reagent, the amount has to be adjusted according to the exact experimental conditions. We achieved transfection efficiencies of ca. $10 \%$ at the cost of cell viability (ca. $40 \%$ survival rate). However, we still had reliable $6.60 \%$ transfection rates with much higher cell viability (ca. $75 \%$ survival rate) at a lower dose of Lipofectamine 2000.

In summary, due to a response to compressive force similar to primary hPDLF, the PDL-hTERT cell line has a good chance to facilitate basic research on periodontal mechanical stress by speeding up in vitro simulations. As a complement to established models using primary hPDLF, this cell line can reduce the need to harvest and cultivate primary cells from donors, which are not always readily available. What might even be a more important benefit is the possibility to transfect this homogeneous cell line, opening a vast array of molecular gain- and loss-of-function studies.

\section{Materials and Methods}

\subsection{Cell Culture Experiments and In Vitro Model for Compressive Mechanical Strain}

The PDL-hTERT cell line [23] was cultured in DMEM high glucose containing sodium pyruvate and GlutaMAX (Gibco, Thermo Fisher Scientific, Schwerte, Germany, 31966-021), 10\% FCS (Bio\&Sell, Feucht, Germany, S 0615) and 1\% PenStrep (Gibco, 15140-122) at $37{ }^{\circ} \mathrm{C}$ and $5 \% \mathrm{CO}_{2}$. Physiological compressive force was applied according to well-established protocols $[3,16,19]$. Cells were seeded in 6-well plates. When cells had reached a confluency of 70\%, gravity-induced compressive force was applied by mechanical loading with sterile glass disks $\left(33 \mathrm{~mm} \varnothing, 17.1 \mathrm{~g}, 2 \mathrm{~g} / \mathrm{cm}^{2}\right.$, Figure 1) for $6 \mathrm{~h}, 24 \mathrm{~h}, 48 \mathrm{~h}$ and $72 \mathrm{~h}$. In parallel, control cells were grown on the same 6-well plates without compressive force. As reference, the starting point was used $(\mathrm{T}=0 \mathrm{~h})$. After the indicated time spans, medium was removed and stored at $-80^{\circ} \mathrm{C}$ until analysis and cells were used for extraction of RNA. Two independent experiments were performed $(n=2)$, each consisting of three wells with or without applied pressure, resulting in six independent samples $(n=6)$.

\subsection{Isolation of RNA and Reverse Transcription}

For extraction of RNA, the Qiagen RNeasy plus kit (Qiagen, Hilden, Germany, 74134) involving a step removing genomic DNA was used according to the manufacturer's instructions. Concentration and purity of RNA was checked photometrically on a Implen NP80 nanophotometer. Absence of proteins was assured by OD260/280 values above 1.8. 1.2 $\mu \mathrm{g}$ of total RNA per sample were reverse transcribed with SCRIPT cDNA synthesis kit (Jena Bioscience, Jena, Germany, PCR-511S) using 
oligo-(dT) $)_{20}$ and random hexamer primers. First strand synthesis was performed at $42{ }^{\circ} \mathrm{C}$ for $10 \mathrm{~min}$ followed by $50^{\circ} \mathrm{C}$ for $60 \mathrm{~min}$. After heat inactivation $\left(10 \mathrm{~min}\right.$ at $\left.70^{\circ} \mathrm{C}\right)$, samples were immediately cooled on ice.

\subsection{Quantitative Real-Time PCR}

To assess cDNA amounts, quantitative real-time PCR was performed. Primers for qRT-PCR were used according to published literature; primer sequences are listed in Table 1.

Table 1. Primers used for qRT-PCR.

\begin{tabular}{|c|c|c|c|c|}
\hline Target Gene & Forward Primer $\left(5^{\prime}-\ldots-3^{\prime}\right)$ & Reverse Primer $\left(5^{\prime}-\ldots-3^{\prime}\right)$ & $\begin{array}{l}\text { Annealing } \\
\text { Temperature }\end{array}$ & Reference \\
\hline$A L P L$ & ACAAGCACTCCСACTTCATCTG & GGTCCGTCACGTTGTTCCTG & $60^{\circ} \mathrm{C}$ & [16] \\
\hline COL1A2 & AGAAACACGTCTGGCTAGGAG & GCATGAAGGCAAGTTGGGTAG & $60^{\circ} \mathrm{C}$ & [16] \\
\hline FN1 & GCCAGTCCTACAACCAGTATTCTC & GCTTGTTCCTCTGGATTGGAAAG & $60{ }^{\circ} \mathrm{C}$ & [16] \\
\hline$I L-6$ & TGGCAGAAAACAACCTGAACC & CСTCAAACTCCAAAAGACCAGTG & $60^{\circ} \mathrm{C}$ & [16] \\
\hline$M-C S F$ & GGAGACCTCGTGCCAAATTA & GGCATTGGGGGTGTTATCTC & $60{ }^{\circ} \mathrm{C}$ & [30] \\
\hline P4HA1 & GCTCTCTGGCTATGAAAATCCTG & GTGCAAAGTCAAAATGGGGTTC & $60^{\circ} \mathrm{C}$ & [16] \\
\hline PPIB & TTCCATCGTGTAATCAAGGACTTC & GCTCACCGTAGATGCTCTTTC & $60{ }^{\circ} \mathrm{C}$ & [16] \\
\hline PTGS2 & GAGCAGGCAGATGAAATACCAGTC & TGTCACCATAGAGTGCTTCCAAC & $60^{\circ} \mathrm{C}$ & [16] \\
\hline$V E G F-A$ & TGCAGACCAAAGAAAGATAGAGC & ACGCTCCAGGACTTATACCG & $58^{\circ} \mathrm{C}$ & [16] \\
\hline
\end{tabular}

Quantitative real-time PCR was performed on a Roche LightCycler 96 with PowerUp SYBR Green Master Mix (Applied Biosystems, Thermo Fisher Scientific, Schwerte, Germany, A25777). Each PCR reaction was performed in technical triplicates, cDNA was pipetted as a 1:12 dilution. All other components were added as a master mix. PCR cycles were as follows: $5 \mathrm{~min} 95^{\circ} \mathrm{C}, 40$ cycles of $10 \mathrm{~s}$ $95^{\circ} \mathrm{C}, 20 \mathrm{~s}$ annealing temp (annealing temperatures are listed in Table 1), $20 \mathrm{~s} 72^{\circ} \mathrm{C}$. Melting curves of PCR products were analyzed to assure their specificity. Relative gene expression was calculated by the $\triangle \triangle \mathrm{Ct}$ method with PPIB as reference gene [16,19].

\subsection{ELISA}

PGE2 secreted into cell supernatant was quantified by a commercially available enzyme-linked immunosorbent assay (ELISA) kit according to manufacturer's instructions (Cayman Chemical, Biomol, Hamburg, Germany, 514010 (96)) with 1:50 dilution of supernatants. Optical density was measured at $450 \mathrm{~nm}$ on a BioTek Synergy H1 microplate reader with eight measurements per data point. Standard curve fit and calculation of concentrations were performed with a Cayman Chemical Excel Spreadsheet.

\subsection{Cell Transfection and Determination of Transfection Rate}

Cells were grown under standard conditions to a confluency of $40 \%$ in 24 well plates. Transfections were performed in triplicate. For transfection with PEI, the following protocol was used: $1.5 \mu \mathrm{g}$ of pEGFP-N1 plasmid was diluted in $150 \mu \mathrm{L}$ DMEM (Gibco, 31966-021), $0.5 \mu \mathrm{L}$ (low amount) or $1.5 \mu \mathrm{L}$ (high amount) of PEI (Sigma-Aldrich, Merck, Darmstadt, Germany, 408727; diluted 1:2262, pH adjusted to 7.0) was added, immediately followed by a ten second mixing step on a vortex mixer. DNA-PEI complexes were allowed to form during a $15 \mathrm{~min}$ incubation period at room temperature. After that $50 \mu \mathrm{L}$ were carefully dripped onto each well and the plate was cautiously shaken immediately. Cel culture medium was changed after $3 \mathrm{~h}$. Transfection with SuperFect (Qiagen, 301305) was performed in the same way, except that $0.66 \mu \mathrm{L}$ (low amount) or $2 \mu \mathrm{L}$ (high amount) of SuperFect were used instead of PEI.

For transfection with Lipofectamine 2000 (Invitrogen, Thermo Fisher Scientific, Schwerte, Germany, 11668-027), $1.5 \mu \mathrm{g}$ pEGFP-N1 were diluted in Opti-MEM medium (Gibco, 31966-021) to a final volume of $75 \mu \mathrm{L}$. In parallel, $0.33 \mu \mathrm{L}$ (low amount) or $1 \mu \mathrm{L}$ (high amount) of Lipofectamine 2000 were diluted in Opti-MEM to a final volume of $75 \mu \mathrm{L}$. Lipofectamine 2000 dilution was added to diluted DNA and 
carefully mixed. After a complex formation period of $5 \mathrm{~min}, 50 \mu \mathrm{L}$ were carefully dripped onto each well and the plate was carefully shaken immediately. The next day, cell culture medium was changed.

After $48 \mathrm{~h}$, cells were fixed with $4 \%$ formaldehyde for $10 \mathrm{~min}$ at room temperature, washed six times with PBS (Gibco ${ }^{\mathrm{TM}}$ 10010056) and permeabilized with 0.1\% Triton X-100 (Carl Roth, Karlsruhe, Germany, 3051.3) in PBS for $10 \mathrm{~min}$. Cell nuclei were visualized by incubation with 4',6-Diamidin-2-phenylindol (DAPI; $1 \mathrm{mg} / \mathrm{mL}$ ) at a 1:5000 dilution for $10 \mathrm{~min}$. After washing with PBS, GFP-autofluorescence and DAPI were photographed on a Leica DMI6000 B inverted microscope equipped with a DFC 360FX camera. For estimation of cell toxicity of transfection mixtures, numbers of DAPI-positive nuclei per field of view were counted and set into relation to numbers of nuclei of non-transfected cells. For calculation of transfection efficiency, GFP-positive transfected cells were counted and set into relation to DAPI-positive nuclei of respective field of views.

\subsection{Statistical Methods}

For each analyte, the arithmetic mean of reference values at $\mathrm{T}=0 \mathrm{~h}$ was set to 1 . All values were calculated relative to this reference. Furthermore, values of samples with applied compressive force were divided by the arithmetic means of respective non-treated control samples. For statistical analyses, Kruskal-Wallis tests were performed in GraphPad Prism 8.3 (GraphPad Software, San Diego, California, USA) by comparing each mean with the mean of the reference ( $\mathrm{T}=0 \mathrm{~h}$ ) with Dunn's multiple comparisons test.

Author Contributions: Conceptualization, M.W. (Matthias Weider), A.S. and L.G.; methodology, M.W. (Matthias Weider), A.S. and G.R.; investigation, M.W. (Matthias Weider), G.R., I.E., and D.A.; resources, D.D. and M.W. (Michael Wegner); writing—original draft preparation, M.W. (Matthias Weider); writing—review and editing, C.L.S., C.K. and L.G.; visualization, M.W. (Matthias Weider); supervision, A.B., J.D., C.K., P.P. and L.G.; project administration, M.W. (Matthias Weider) All authors have read and agreed to the published version of the manuscript.

Funding: This research was supported by the Interdisciplinary Center for Clinical Research (IZKF) at the University Hospital of the University of Erlangen-Nuremberg, grant number F3-32.

Acknowledgments: We thank Beate Winner and Thomas Brabletz at the Nikolaus-Fiebiger-Zentrum in Erlangen for the possibility to use their laboratory equipment.

Conflicts of Interest: The authors declare no conflict of interest.

\section{Abbreviations}

ELISA enzyme-linked immunosorbent assay

hPDLF human periodontal ligament fibroblasts

OTM orthodontic tooth movement

PDL periodontal ligament

PEI Polyethylenimine

qRT-PCR quantitative reverse transcriptase polymerase chain reaction

SEM standard error of the mean

\section{References}

1. Lekic, P.; McCulloch, C.A.G. Periodontal ligament cell populations: The central role of fibroblasts in creating a unique tissue. Anat. Rec. 1996, 245, 327-341. [CrossRef]

2. Beertsen, W.; McCulloch, C.A.; Sodek, J. The periodontal ligament: A unique, multifunctional connective tissue. Periodontol 2000 1997, 13, 20-40. [CrossRef] [PubMed]

3. Kanzaki, H.; Chiba, M.; Shimizu, Y.; Mitani, H. Periodontal ligament cells under mechanical stress induce osteoclastogenesis by receptor activator of nuclear factor kappaB ligand up-regulation via prostaglandin E2 synthesis. J. Bone Miner. Res. 2002, 17, 210-220. [CrossRef] [PubMed]

4. Rios, H.F.; Ma, D.; Xie, Y.; Giannobile, W.V.; Bonewald, L.F.; Conway, S.J.; Feng, J.Q. Periostin is essential for the integrity and function of the periodontal ligament during occlusal loading in mice. J. Periodontol. 2008, 79, 1480-1490. [CrossRef] [PubMed] 
5. Gilroy, D.W.; Bishop-Bailey, D. Lipid mediators in immune regulation and resolution. Br. J. Pharmacol. 2019, 176, 1009-1023. [CrossRef]

6. Mitchell, J.A.; Kirkby, N.S. Eicosanoids, prostacyclin and cyclooxygenase in the cardiovascular system. Br. J. Pharmacol. 2019, 176, 1038-1050. [CrossRef]

7. Kaku, M.; Motokawa, M.; Tohma, Y.; Tsuka, N.; Koseki, H.; Sunagawa, H.; Arturo Marquez Hernandes, R.; Ohtani, J.; Fujita, T.; Kawata, T.; et al. VEGF and M-CSF levels in periodontal tissue during tooth movement. Biomed. Res. 2008, 29, 181-187. [CrossRef]

8. Meikle, M.C. The tissue, cellular, and molecular regulation of orthodontic tooth movement: 100 years after Carl Sandstedt. Eur. J. Orthod. 2006, 28, 221-240. [CrossRef]

9. Brooks, P.J.; Heckler, A.F.; Wei, K.; Gong, S.G. M-CSF accelerates orthodontic tooth movement by targeting preosteoclasts in mice. Angle Orthod. 2011, 81, 277-283. [CrossRef]

10. Theill, L.E.; Boyle, W.J.; Penninger, J.M. RANK-L and RANK: T cells, bone loss, and mammalian evolution. Annu Rev. Immunol. 2002, 20, 795-823. [CrossRef]

11. Boyce, B.F.; Xing, L. Functions of RANKL/RANK/OPG in bone modeling and remodeling. Arch. Biochem Biophys 2008, 473, 139-146. [CrossRef] [PubMed]

12. Roberts, W.E.; Huja, S.; Roberts, J.A. Bone modeling: Biomechanics, molecular mechanisms, and clinical perspectives. Semin. Orthod. 2004, 10, 123-161. [CrossRef]

13. Li, Y.; Zheng, W.; Liu, J.S.; Wang, J.; Yang, P.; Li, M.L.; Zhao, Z.H. Expression of osteoclastogenesis inducers in a tissue model of periodontal ligament under compression. J. Dent. Res. 2011, 90, 115-120. [CrossRef] [PubMed]

14. Li, Z.; Yu, M.; Jin, S.; Wang, Y.; Luo, R.; Huo, B.; Liu, D.; He, D.; Zhou, Y.; Liu, Y. Stress Distribution and Collagen Remodeling of Periodontal Ligament During Orthodontic Tooth Movement. Front. Pharm. 2019, 10, 1263. [CrossRef] [PubMed]

15. Huang, X.F.; Zhao, Y.B.; Zhang, F.M.; Han, P.Y. Comparative study of gene expression during tooth eruption and orthodontic tooth movement in mice. Oral Dis. 2009, 15, 573-579. [CrossRef]

16. Schröder, A.; Bauer, K.; Spanier, G.; Proff, P.; Wolf, M.; Kirschneck, C. Expression kinetics of human periodontal ligament fibroblasts in the early phases of orthodontic tooth movement. J. Orofac. Orthop. 2018, 79, 337-351. [CrossRef]

17. Janjic Rankovic, M.; Docheva, D.; Wichelhaus, A.; Baumert, U. Effect of static compressive force on in vitro cultured PDL fibroblasts: Monitoring of viability and gene expression over 6 days. Clin. Oral Investig. 2020, 24, 2497-2511. [CrossRef]

18. Kanzaki, H.; Chiba, M.; Shimizu, Y.; Mitani, H. Dual regulation of osteoclast differentiation by periodontal ligament cells through RANKL stimulation and OPG inhibition. J. Dent. Res. 2001, 80, 887-891. [CrossRef]

19. Kirschneck, C.; Batschkus, S.; Proff, P.; Köstler, J.; Spanier, G.; Schröder, A. Valid gene expression normalization by RT-qPCR in studies on hPDL fibroblasts with focus on orthodontic tooth movement and periodontitis. Sci. Rep. 2017, 7, 14751. [CrossRef]

20. Memmert, S.; Damanaki, A.; Weykopf, B.; Rath-Deschner, B.; Nokhbehsaim, M.; Götz, W.; Gölz, L.; Till, A.; Deschner, J.; Jäger, A. Autophagy in periodontal ligament fibroblasts under biomechanical loading. Cell Tissue Res. 2019, 378, 499-511. [CrossRef]

21. Memmert, S.; Nogueira, A.V.B.; Damanaki, A.; Nokhbehsaim, M.; Rath-Deschner, B.; Götz, W.; Gölz, L.; Cirelli, J.A.; Till, A.; Jäger, A.; et al. Regulation of the autophagy-marker Sequestosome 1 in periodontal cells and tissues by biomechanical loading. J. Orofac Orthop. 2020, 81, 10-21. [CrossRef] [PubMed]

22. Kirschneck, C.; Proff, P.; Maurer, M.; Reicheneder, C.; Römer, P. Orthodontic forces add to nicotine-induced loss of periodontal bone. J. Orofac. Orthop./Fortschr. Der. Kieferorthopädie 2015, 76, 195-212. [CrossRef] [PubMed]

23. Docheva, D.; Padula, D.; Popov, C.; Weishaupt, P.; Pragert, M.; Miosge, N.; Hickel, R.; Bocker, W.; Clausen-Schaumann, H.; Schieker, M. Establishment of immortalized periodontal ligament progenitor cell line and its behavioural analysis on smooth and rough titanium surface. Eur. Cell Mater. 2010, 19, 228-241. [CrossRef] [PubMed]

24. Kirschneck, C.; Meier, M.; Bauer, K.; Proff, P.; Fanghänel, J. Meloxicam medication reduces orthodontically induced dental root resorption and tooth movement velocity: A combined in vivo and in vitro study of dental-periodontal cells and tissue. Cell Tissue Res. 2017, 368, 61-78. [CrossRef] 
25. Schröder, A.; Nazet, U.; Neubert, P.; Jantsch, J.; Spanier, G.; Proff, P.; Kirschneck, C. Sodium-chloride-induced effects on the expression profile of human periodontal ligament fibroblasts with focus on simulated orthodontic tooth movement. Eur. J. Oral Sci. 2019, 127, 386-395. [CrossRef]

26. Kirschneck, C.; Küchler, E.C.; Wolf, M.; Spanier, G.; Proff, P.; Schröder, A. Effects of the Highly COX-2-Selective Analgesic NSAID Etoricoxib on Human Periodontal Ligament Fibroblasts during Compressive Orthodontic Mechanical Strain. Mediat. Inflamm. 2019. [CrossRef]

27. Sari, E.; Olmez, H.; Gürton, A.U. Comparison of some effects of acetylsalicylic acid and rofecoxib during orthodontic tooth movement. Am. J. Orthod. Dentofac. Orthop. 2004, 125, 310-315. [CrossRef]

28. Shetty, N.; Patil, A.K.; Ganeshkar, S.V.; Hegde, S. Comparison of the effects of ibuprofen and acetaminophen on PGE2 levels in the GCF during orthodontic tooth movement: A human study. Prog Orthod. 2013, 14, 6. [CrossRef]

29. Schröder, A.; Küchler, E.C.; Omori, M.; Spanier, G.; Proff, P.; Kirschneck, C. Effects of ethanol on human periodontal ligament fibroblasts subjected to static compressive force. Alcohol 2019, 77, 59-70. [CrossRef]

30. Okugawa, Y.; Toiyama, Y.; Ichikawa, T.; Kawamura, M.; Yasuda, H.; Fujikawa, H.; Saigusa, S.; Ohi, M.; Araki, T.; Tanaka, K.; et al. Colony-stimulating factor-1 and colony-stimulating factor-1 receptor co-expression is associated with disease progression in gastric cancer. Int. J. Oncol. 2018, 53, 737-749. [CrossRef]

Publisher's Note: MDPI stays neutral with regard to jurisdictional claims in published maps and institutional affiliations.

(C) 2020 by the authors. Licensee MDPI, Basel, Switzerland. This article is an open access article distributed under the terms and conditions of the Creative Commons Attribution (CC BY) license (http://creativecommons.org/licenses/by/4.0/). 